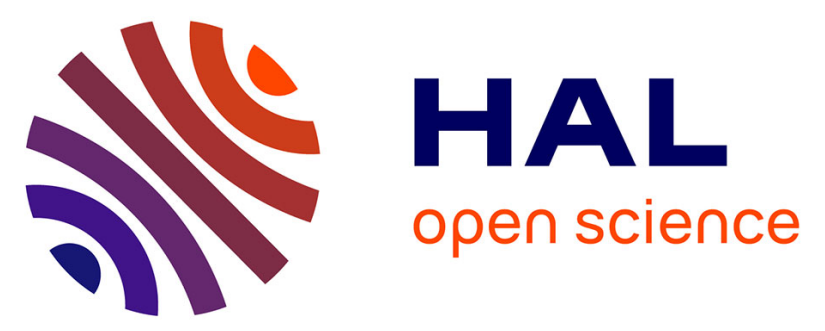

\title{
Metabolic processes and carbon nutrient exchanges between host and pathogen sustain the disease development during sunflower infection by Sclerotinia sclerotiorum.
}

Cécile Jobic, Anne-Marie Boisson, Elisabeth Gout, Christine Rascle, Michel Fèvre, Pascale Cotton, Richard Bligny

\section{To cite this version:}

Cécile Jobic, Anne-Marie Boisson, Elisabeth Gout, Christine Rascle, Michel Fèvre, et al.. Metabolic processes and carbon nutrient exchanges between host and pathogen sustain the disease development during sunflower infection by Sclerotinia sclerotiorum.. Planta, 2007, 226 (1), pp.251 - 265. 10.1007/s00425-006-0470-2 . hal-00134821

\section{HAL Id: hal-00134821 \\ https://hal.science/hal-00134821}

Submitted on 15 Mar 2007

HAL is a multi-disciplinary open access archive for the deposit and dissemination of scientific research documents, whether they are published or not. The documents may come from teaching and research institutions in France or abroad, or from public or private research centers.
L'archive ouverte pluridisciplinaire HAL, est destinée au dépôt et à la diffusion de documents scientifiques de niveau recherche, publiés ou non, émanant des établissements d'enseignement et de recherche français ou étrangers, des laboratoires publics ou privés. 
5 Metabolic processes and carbon nutrient exchanges between host and pathogen sustain the disease development during sunflower infection by

7 Sclerotinia sclerotiorum

Cécile Jobic, Anne-Marie Boisson, Elisabeth Gout, Christine Rascle, Michel Fèvre, 11 Pascale Cotton, Richard Bligny UMR5122, Unité Microbiologie et Génétique, Bat Lwoff, 10 rue Raphaël Dubois, Villeurbanne, F-69622,

16 France

17 E-mail :cotton@biomserv.univ-lyon1.fr

18 Tel.: 33-4-72-44-85-43

19 Fax: $33-4-72-43-11-81$ 


\section{Abstract}

3 Interactions between the necrotrophic fungus Sclerotinia sclerotiorum and one of its hosts,

4 Helianthus annuus L., were analyzed during fungal colonization of plant tissues.

5 Metabolomic analysis, based on ${ }^{13} \mathrm{C}$ - and ${ }^{31} \mathrm{P}-\mathrm{NMR}$ spectroscopy, was used to draw up the

6 profiles of soluble metabolites of the two partners before interaction, and to trace the fate of metabolites specific of each partner during colonization. In sunflower cotyledons, the main soluble carbohydrates were glucose, fructose, sucrose and glutamate. In S. sclerotiorum extracts, glucose, trehalose and mannitol were the predominant soluble carbon stores. During infection, a decline in sugars and amino acids was observed in the plant and fungus total content. Sucrose and fructose, initially present almost exclusively in plant, were reduced by $85 \%$. We used a biochemical approach to correlate the disappearance of sucrose with the expression and the activity of fungal invertase. The expression of two hexose transporters, Sshxt1 and Sshxt2, was enhanced during infection. A database search for hexose transporters homologues in the S. sclerotiorum genome revealed a multigenic sugar transport system. Furthermore, the composition of the pool of reserve sugars and polyols during infection was investigated. Whereas mannitol was produced in vitro and accumulated in planta, glycerol was exclusively produced in infected tissues and increased during colonization. The hypothesis that the induction of glycerol synthesis in S. sclerotiorum exerts a positive effect on osmotic protection of fungal cells and favours fungal growth in plant tissues is discussed. Taken together, our data revealed the importance of carbon-nutrient exchanges during the necrotrophic pathogenesis of S. sclerotiorum.

Keywords Acid invertase . Helianthus . Hexose transport . NMR spectroscopy . Polyols . Sclerotinia

Abbreviations GPC: glycerylphosphoryl-choline . GPE: glycerylphosphoryl-ethanolamine . GPG: glycerylphosphoryl-glycerol . GPI: glycerylphosphoryl-inositol . hpi: hours post inoculation . PCA: perchloric acid . PGA: phosphoglyceric acid . Q-PCR: quantitative polymerase chain reaction . UDP-GlcNAc: uridine -5'-diphosphate-N-acetylglucosamine 


\section{Introduction}

2 As a necrotrophic fungus, Sclerotinia sclerotiorum is able to feed on dead cells and is one of the most non-specific and omnivorous plant pathogens (Boland and Hall 1994). Two main pathogenicity factors, secretion of oxalic acid and hydrolytic enzymes, act in concert to macerate plant tissues and generate necrosis. Degradation of plant cell wall components and host tissues is linked to the concerted production of a wide and complex range of extracellular lytic enzymes such as cellulases, hemicellulases, pectinases and proteases. Sequentially secreted by the fungus, lytic enzymes facilitate penetration, colonization and maceration but also generate an important source of nutrients (reviewed by Bolton et al. 2006). Secreted oxalic acid acidifies the apoplastic space, sequesters calcium, interferes with plant defences and appears to be an essential determinant of pathogenicity (Maxwell and Lumdsen 1970; Hegedus and Rimmer 2005). The secretion of oxalic acid by S. sclerotiorum results in formation of lesions and water-soaked tissues, in advance of the invading fungal hyphae, rapidly expanding as a frontal zone of hosts cells impaired in their viability (Lumdsen and Dow 1973). To complete their life cycle in planta, pathogenic fungi must also be able to gain nutrients from plant cells.

Metabolic interactions between plants and fungi have been conducted on biotrophic and mycorrhizal fungi in most cases. Mycorrhizae are characterized by the uptake of minerals from the soil by fungal hyphae, followed by their transfer to the root cells. In return, plant carbohydrates are transferred to the fungal symbiont and their utilization is oriented towards the synthesis of short chain polyols (Martin et al. 1998; Bago et al. 1999). Free amino acids also represent an important sink of absorbed and assimilated carbon (Martin et al. 1998).

Biotrophs cause little damage to the host plant, and derive energy from living cells. They produce extensions into plant cells, haustoria, linked to maintain basic compatibility between fungi and their host plants and to nutrient uptake (Mendgen et al. 2000). During a compatible interaction, competition of the parasite with natural sink organs of the host, results in considerable modification of photoassimilate production and alterations in partitioning within host tissues (Scholes et al. 1994; Hall and Williams 2000; Abood and Lösel 2003). A common feature is a reduction in the rate of photosynthesis (Tang et al. 1996; Chou et al. 2000). During infection with Albugo candida, the decrease in photosynthesis was correlated with an accumulation of carbohydrates in leaves of Arabidopsis thaliana (Tang et al. 1996; Chou et al. 2000). Direct analysis of sugar composition of the leaf apoplast of tomato infected by Cladosporium fulvum indicated high levels of sucrose accumulated during early stages of infection, that could be linked to the expression of plant or fungal invertases (Joosten et al. 
1 1990). The induction of a sink-specific cell-wall invertase at the site of infection appears to be 2 a general response to a biotic stress (Scholes et al. 1994; Fotopoulos et al. 2003; Roitsch et al. 3 2003; Voegele et al. 2006). Molecular analysis of compatible biotrophic interactions suggested that nutrients were mainly taken up in form of hexoses and amino acids, in accordance with the strong expression of amino acids and hexoses permeases in haustoria (Voegele et al. 2001; Struck et al. 2004). As shown for the compatible interactions Uromyces fabae-Vicia faba or C. fulvum-Lycopsersicon esculentum, much of the carbohydrates supplied to fungal biotrophic pathogens could be converted later in the infection cycle into the C6polyol mannitol, that could play a pivotal role in suppression of ROS-related defence mechanisms or in carbon storage (Noeldner et al. 1994; Voegele et al. 2005).

The nature of available nutrient supplies metabolized by necrotrophic fungi during infection has received little attention up to now. Studies dedicated to carbohydrate and invertase activity changes during necrotrophic interactions are scarce and mainly focused on plant. Upon infection with Botrytis cinerea, photosynthetic gene expression was downregulated in tomato plant tissues and expression of a cell wall invertase was induced by the pathogen (Berger et al. 2004). Accumulation of invertase in the cell walls of tomato plants was induced by Fusarium oxysporum in susceptible and resistant hosts (Benhamou 1991). An elicitor preparation of the tomato pathogen $F$. oxysporum also activated invertase gene expression in tomato suspension culture cells (Sinha et al. 2002). In this study, we report a metabolic study of the necrotrophic interaction between S. sclerotiorum and cotyledonary leaves of sunflower based on NMR spectroscopy used to monitor cellular metabolism (Roberts and Jardetsky 1981; Shachar-Hill and Pfeffer 1996; Ratcliffe and Shachar-Hill 2001). In order to analyze metabolic processes that promote fungal development in plant tissues, we established the profiles of soluble metabolites for each partner and followed the quantitative modifications of these metabolites during the course of infection. Our results indicate a progressive exhaustion of plant carbohydrate stores in favour of the accumulation of glycerol of fungal origin. Fungal elements that could be linked to the decrease of plant sugars have been investigated. Increases of invertase activity and in planta expression of fungal hexose transporters are described.

\section{Materials and methods}


1 S. sclerotiorum S5 was initially provided by BayerCropScience, Lyon, France. The strain was

2 maintained on potato dextrose agar. For NMR characterization, mycelia were grown for $48 \mathrm{~h}$ on solid minimal medium (Riou et al. 1991) supplemented with 2\% glucose. Mycelia were frozen in liquid nitrogen and stored at $-80^{\circ} \mathrm{C}$.

Pathogenicity tests

Phytopathogenicity assays were performed on sunflower cotyledons as hosts. Sunflower plants (Mirasol variety) were purchased from Limagrain (Riom, France). Sunflowers were grown at $25^{\circ} \mathrm{C}$ with a 14-h light period per day. Cotyledons from one-week-old germlings were infected at the end of a dark period by depositing a 4-mm-mycelium disk at the centre of the adaxial side. At $8 \mathrm{hpi}$, mycelium discs were tightly attached to the surface of cotyledons, indicating the penetration of fungal hyphae into plant. Necrosis was detectable by the apparition of a brown colour surrounding the starting point of infection. The necrosed and macerated region corresponded to a 2-mm-zone surrounding the mycelium discs 16 hpi. 24 hpi, half of the cotyledons were macerated and necrosed. At 48 hpi, the whole cotyledon was infected. Cotyledons were harvested after the different stages of symptoms development (8, 16, 24, 36, 48 hpi). For invertase assays and some NMR experiments that were realized on fractions of infected cotyledons, plugs of mycelium were deposited near the tip of the leaves, in order to easily separate two distinct zones at different stages of infection: a non-invaded region and an invaded region. Absence of fungus was confirmed by microscope observation and by the absence of detected UDP-GlcNAc in the spectra. Samples were then frozen in liquid nitrogen.

NMR spectroscopy

PCA extracts were prepared from $10 \mathrm{~g}$ of $H$. annuus cotyledons, or $10 \mathrm{~g}$ of S. sclerotiorum mycelia, or $10 \mathrm{~g}$ of infected cotyledons, according to the method described by Aubert et al. (1996). Spectra of neutralized PCA extracts were recorded in a Fourier transform NMR spectrometer (model AMX 400, Bruker Billerica MA) equipped with a 10-mm multinuclear probe tuned at 161.9 or $100.6 \mathrm{MHz}$ for ${ }^{31} \mathrm{P}$ - or ${ }^{13} \mathrm{C}$-NMR studies, respectively. The deuterium resonance of ${ }^{2} \mathrm{H}_{2} \mathrm{O}\left(100 \mu \mathrm{l}\right.$ added per $\mathrm{ml}$ of extract) was used as a lock signal. ${ }^{31} \mathrm{P}-\mathrm{NMR}$ acquisition conditions: $70^{\circ}$ pulses $(15-\mu \mathrm{s})$ at 3.6-s intervals; spectral width, $8.2 \mathrm{kHz}$; Waltz-16 ${ }^{1} \mathrm{H}$ decoupling sequence with $1 \mathrm{~W}$ decoupling during acquisition and $0.5 \mathrm{~W}$ during delay; free 
1 induction decays collected as 8,000 data points, zero-filled to 16,000 , and processed with a 2 0.2-Hz exponential line broadening. Spectra were referenced to methylene diphosphonic acid, $3 \mathrm{pH} 8.9$, at $16.38 \mathrm{ppm}$. Divalent paramagnetic cations were chelated by addition of corresponding amounts of 1,2-cyclohexylenedinitrilotetraacetic acid (CDTA). ${ }^{13} \mathrm{C}-\mathrm{NMR}$ acquisition conditions: $90^{\circ}$ pulses $(19-\mu \mathrm{s})$ at 6 -s intervals; spectral width, $20 \mathrm{kHz}$; Waltz-16 ${ }^{1} \mathrm{H}$ decoupling sequence with $2.5 \mathrm{~W}$ decoupling during acquisition and $0.5 \mathrm{~W}$ during the delay; free induction decays collected as 32,000 data points, zero-filled to 64,000 , and processed with a $0.2-\mathrm{Hz}$ exponential line broadening. Spectra were referenced to hexamethyldisiloxane at $2.7 \mathrm{ppm}$. $\mathrm{Mn}^{2+}$ ions were chelated by addition of $1 \mathrm{mM}$ CDTA. Assignments were made after running series of standard solutions of known compounds at $\mathrm{pH}$ 7.5 and after the addition of these compounds to PCA extracts as previously described (Aubert et al. 1996). Identified compounds were quantified by comparison of the surface of their resonance peaks to the surface of the resonance peaks of standards added to samples before grinding. Fully relaxed conditions during spectra acquisition (pulses at 20-s intervals) were used for quantification. The standards utilized were methyl phosphonate and maleate for ${ }^{31} \mathrm{P}$ - and ${ }^{13} \mathrm{C}-\mathrm{NMR}$ analyses.

Preparation of protein extracts and detection of invertase activity

Frozen healthy plant material and infected plant tissues were ground to a fine powder in liquid nitrogen. Ground tissues were resuspended in cold extraction buffer (100 mM Tris pH 7.5, 2.5 mM EDTA, $5 \mathrm{mM}$ DTT, $1 \mathrm{mM}$ PMSF, $5 \mu \mathrm{g} \mathrm{ml}^{-1}$ pepstatin and $10 \mathrm{mM}$ Chaps) and incubated $20 \mathrm{~min}$ at $4^{\circ} \mathrm{C}$. Extracts were then centrifuged at $13,000 \mathrm{~g}$ for $30 \mathrm{~min}$ at $4^{\circ} \mathrm{C}$. Supernatants containing total proteins were collected and stored at $-20^{\circ} \mathrm{C}$. Secreted proteins from in vitro culture filtrates were concentrated by $\left(\mathrm{NH}_{4}\right)_{2} \mathrm{SO}_{4}$ precipitation (80\% saturation) overnight at $4^{\circ} \mathrm{C}$. After centrifugation at $12,000 \mathrm{~g}$ for $30 \mathrm{~min}$ at $4^{\circ} \mathrm{C}$, the proteins present in pellets were dissolved in distilled water and stored at $-20^{\circ} \mathrm{C}$. Protein concentration was determined using the BioRad protein Assay (BioRad, Marnes la Coquette, France), with BSA as the standard. Proteins $(10 \mu \mathrm{g})$ extracted from healthy and infected tissues or recovered from culture filtrates were separated by isoelectric focusing (IEF) using ultrathin polyacrylamide gels (Servalyt Precotes, pH 3-10, Serva Heidelberg, Germany). Gels were focused for $1.5 \mathrm{~h}$ at $3 \mathrm{~W}, 1700 \mathrm{~V}$ and $1 \mathrm{~mA}$. A part of the slab gel was stained with Coomassie brillant blue for protein visualization, the other part was used to reveal invertase activities by zymography, according 
1 containing $500 \mathrm{mM}$ sucrose in $50 \mathrm{mM}$ sodium acetate $\mathrm{pH} 5.6$ or 4 or in $50 \mathrm{mM}$ Hepes buffer $2 \mathrm{pH} \mathrm{7}$, at $30^{\circ} \mathrm{C}$ for $30 \mathrm{~min}$. Invertase isoforms were revealed by incubating the gels in $1 \%$ 3 2,3,5-triphenyltetrazolium chloride monohydrate (Sigma, St Quentin-Fallavier, France) in $4 \quad 0.25 \mathrm{M}$ hot $\mathrm{NaOH}$. Red colour development was stopped with $1 \%$ acetic acid.

Immunological methods

Proteins $(10 \mu \mathrm{g})$ were separated by SDS polyacrylamide gel electrophoresis (SDS PAGE) according to Laemmli (1970), using the miniprotean-2D system (BioRad, Marnes la Coquette, France). After migration in a 7\% acrylamide gel, proteins were blotted onto nitrocellulose (Schleicher and Schuell Gmbh, Dassel, Germany) according to Towbin et al. (1979). Nitrocellulose membranes were incubated for $2 \mathrm{~h}$ at room temperature in $5 \%$ non fat dry milk, $150 \mathrm{mM} \mathrm{NaCl}, 50 \mathrm{mM}$ Tris- $\mathrm{HCl} \mathrm{pH}$ 7.4, 0.01\% Tween 20, rinsed in $150 \mathrm{mM} \mathrm{NaCl}, 50 \mathrm{mM}$ Tris-Hcl pH 7.4, 0.05\% Tween 20 and then incubated $1 \mathrm{~h}$ in the presence of antisera. Primary antisera were used at a dilution of 1:5000. Antisera raised against tobacco cell wall invertase were kindly provided by Dr S. Greiner (Heidelberger Institut für Pflanzenwissenschaften, Germany). Antisera raised against Candida albicans invertase were purchased from USBiological (Euromedex, Mundolsheim, France). Incubations with anti-rabbit IgGs (antitobacco invertase, 1:20000 and anti-C. albicans invertase, 1:2000) was followed by detection using enhanced chemiluminescent substrate (Pierce Super Signal Substrate, Pierce PerbioFrance, Brebières, France). Cross reactivity of the antisera was tested. No proteins from healthy plant tissues extracts were detected by anti fungal antisera. As well, antiplant antisera did not detect any protein extracted from the mycelium of $S$. sclerotiorum or secreted by the fungus.

Cloning Sshxt1 and Sshxt2 genes

EST sequences (BfCond010nd BfCon@110from the related necrotrophic fungus Botrytis cinerea, deposited in the public databases (COGEME phytopathogen EST databases, http://cogeme.ex.ac.uk/) as putative hexose transporters (Soanes et al. 2002), were used as probes to screen at low stringency the genomic EMBL3 library of S. sclerotiorum. For Sshxt1, a 205-bp B. cinerea genomic DNA fragment was amplified using the sense primer 5'- 
GATCTTGGGTCTGCGATGAC-3' and the antisense primer 5'-

2 CTGGTGCCGTTCTTATCTG-3' were used to amplify a 300-bp B. cinerea genomic DNA.

$325 \mathrm{ng}$ of $B$. cinerea genomic DNA were used as template. PCR conditions were as follows:

4 after denaturation at $94^{\circ} \mathrm{C}$ for $5 \mathrm{~min}$, annealing of the primers was done at $54^{\circ} \mathrm{C}$ to amplify the probe used to clone $S s h x t 1$ and at $60^{\circ} \mathrm{C}$ to amplify the probe used to clone $s s h x t 2$. After an extension step at $72^{\circ} \mathrm{C}$ for $1 \mathrm{~min}$, a final elongation step at $73^{\circ} \mathrm{C}$ for 8 min was added for 30 cycles. Each amplified fragment was sequenced and used to screen the library at low stringency $\left(37^{\circ} \mathrm{C}, 50 \%\right.$ formamide, 5 圈 SSC). One recombinant phage giving the strongest hybridization signal for each gene was chosen for further studies. Subcloning and routine procedures were performed with standard protocols (Sambrook 1989). Sequences of Sshxt1 and Sshxt2 are available in GenBank under the following accession no.: AY647267 and AY647268 respectively.

RNA isolation and Q-PCR

RNA was extracted from plant material frozen in liquid nitrogen and kept at $-80^{\circ} \mathrm{C}$. Samples were ground in liquid nitrogen, and total RNA was purified by using RNeasy mini spin column as described by manufacturers (Qiagen, Courtabeuf, France). Transcripts of Sshxt1 were amplified using the sense primer 5'-GGTGTCGAAGAATCCCATCCA-3' and the antisense primer 5'-GTGCTGGCAAAACCGACGAT-3'. Transcripts of Sshxt2 were amplified using the sense primer 5'-ACTACTATGTGCTTGTCTTTGC-3' and the antisense primer 5'-GATGCTGCTTCCCAAACGCCATTA-3'. To detect transcripts of the $S$. sclerotiorum actin gene Ssact1, the sense primer 5'-CTTCGTGTAGCACCAGAGGA-3' and the antisense primer 5'-ATGTTACCATACAAATCCTTA-3' were used. For Q-PCR analysis, total RNA was DNaseI treated (RQ1 RNase free DNase, Promega, Charbonnières, France) to remove genomic DNA. Absence of DNA was analyzed by performing a PCR reaction similar to the real-time PCR program, on the DNasel-treated RNA using Taq-DNA polymerase (Promega, Charbonnières, France). Q-PCR experiments were performed using the one-step QuantiTect SYBR Green RT-PCR kit (Qiagen, Courtabeuf, France) according to the instructions of the manufacturer. Reactions were performed in a final volume of $20 \mu 1$, using 1 $\mu \mathrm{g}$ of total RNA, $1 \mu \mathrm{M}$ of each primer, $10 \mu \mathrm{l}$ of QuantiTec SYBR Green RT-PCR Master Mix (containing Hot Start Taq DNA polymerase, QuantiTect SYBR Green RT-PCR buffer, dNTP mix, SYBR Green and $5 \mathrm{mM} \mathrm{MgCl} 2$ ). The amplification was effected in the LightCycler 
cDNA synthesis, $15 \mathrm{~min}$ at $95^{\circ} \mathrm{C}$ to activate the Hot Start DNA polymerase and 45 cycles of amplification as follows: $15 \mathrm{~s}$ at $94^{\circ} \mathrm{C}, 30 \mathrm{~s}$ at $60^{\circ} \mathrm{C}$ for $S \operatorname{sh} x t 1,54^{\circ} \mathrm{C}$ for $S s h x t 2$ and $60^{\circ} \mathrm{C}$ for Ssact 1 and $30 \mathrm{~s}$ at $72^{\circ} \mathrm{C}$. Relative quantification was based on the $\mathrm{C}_{\mathrm{T}}$ method using Ssactl as a calibrator reference. Amplifications were done in triplicate.

\section{Results}

Metabolic characterization of plant and fungal pathogen

Perchloric acid extracts of healthy cotyledonary leaves collected from 8-d-old H. annuиs germlings and of S. sclerotiorum mycelia collected after saprophytic growth on minimal glucose medium were analyzed using ${ }^{13} \mathrm{C}$ - and ${ }^{31} \mathrm{P}-\mathrm{NMR}$ spectroscopy. Representative spectra are shown in figures 1 and 2, and comparative data are given in Table 1.

In $H$. annuus cotyledon extracts, the main stores of soluble carbohydrates detected by ${ }^{13} \mathrm{C}-\mathrm{NMR}$ (Fig. 1) were glucose, fructose and sucrose $\left(63,40\right.$ and $11 \mu \mathrm{mol} \mathrm{g}{ }^{-1} \mathrm{FW}$ of plant tissues, respectively). Plants do not accumulate trehalose. Inositol $\left(10 \mu \mathrm{mol} \mathrm{g}^{-1} \mathrm{FW}\right)$ was the only detected polyol. The most abundant Krebs cycle intermediates were fumarate, malate, succinate and citrate. Glutamate $\left(18 \mu \mathrm{mol} \mathrm{g}{ }^{-1} \mathrm{FW}\right)$ was the main amino acid store. The concentration of alanine, the second unambiguously identified amino acid, was 18 times lower. The most abundant compound measured by ${ }^{31} \mathrm{P}-\mathrm{NMR}$ (Fig. 2b) was inorganic phosphate $\left(2.5 \mu \mathrm{mol} \mathrm{g}{ }^{-1} \mathrm{FW}\right)$. Among identified P-compounds (from upfield to downfield): glucose-6-P, glycerol-3-P, PGA, P-choline, two phosphodiesters, GPG and GPI were detected. Nucleotides (mainly ATP), pyridine nucleotides (NAD and NADP), UDP-glucose and UDP-galactose were also detected. The abundance of GPG and GPI may be related to membrane traffic accompanying the first steps of growth of the germlings (Aubert et al. 1996).

In S. sclerotiorum extracts, main stores of soluble carbohydrates (Fig. 1) were glucose $\left(115 \mu \mathrm{mol} \mathrm{g} \mathrm{g}^{-1} \mathrm{FW}\right)$ and trehalose $\left(26 \mu \mathrm{mol} \mathrm{g}{ }^{-1} \mathrm{FW}\right)$. Contrary to $H$. annuus, fructose and sucrose stores were negligible in S. sclerotiorum. Mannitol $\left(27 \mu \mathrm{mol} \mathrm{g}{ }^{-1} \mathrm{FW}\right)$ was the only abundant polyol, while glycerol, arabitol and erythritol, commonly found in other fungi (Jennings 1984) were below the threshold of ${ }^{13} \mathrm{C}$-NMR detection. Malate and fumarate were the two main stores of Krebs cycle intermediates. Like in H. annuus cotyledons, glutamate $\left(17 \mu \mathrm{mol} \mathrm{g}{ }^{-1} \mathrm{FW}\right)$ was the main store of amino acid. Alanine $\left(8.0 \mu \mathrm{mol} \mathrm{g}{ }^{-1} \mathrm{FW}\right)$ was 8 times more abundant than in plant. Here again, the most abundant compound measured by ${ }^{31} \mathrm{P}$ - 
1 NMR (Fig. 2a) was inorganic phosphate $\left(2.7 \mu \mathrm{mol} \mathrm{g}{ }^{-1}\right.$ FW). Glucose-6-P, PGA, ATP, UDP2 glucose and UDP-galactose were equally detected in mycelium and in plant tissues. In contrast, there were striking differences concerning UDP-GlcNAc, trehalose-6-P, gluconate6-P, P-choline and phosphodiesters. UDP-GlcNAc was the major P-compound in mycelium $\left(1.4 \mu \mathrm{mol} \mathrm{g} \mathrm{g}^{-1} \mathrm{FW}\right)$ whereas it was only present as a trace in cotyledons. In fungi, UDPGlcNAc is predominantly involved in the synthesis of chitin, a structural constituent carbohydrate polymer of cell wall and septum with glucans (Cabib et al. 1991). Similarly, trehalose-6-P, which was not detected in cotyledons, was relatively abundant in mycelium $\left(0.19 \mu \mathrm{mol} \mathrm{g} \mathrm{g}^{-1} \mathrm{FW}\right)$, in accordance with the presence of trehalose. GPC and GPE were the most abundant P-diesters. Interestingly, though glycerol-3-P was present in both partners grown in vitro, glycerol was detected in none of them.

Metabolic profiling during infection

As control experiments, we first verified that the NMR profiles of non infected cotyledons, maintained in the same growth conditions as inoculated cotyledons for a $48 \mathrm{~h}$ period of time equivalent to the course of infection, did not change significantly. Moreover, NMR spectra of samples collected 0 hpi were realized. At the initial stage of infection, the major components from fungal origin (UDP-GlcNAc, mannitol, trehalose) were not detectable. Analysis of the spectra revealed profiles identical to that of healthy cotyledons profiles. On the contrary, ${ }^{13} \mathrm{C}$ and ${ }^{31} \mathrm{P}-\mathrm{NMR}$ spectra of $H$. annuus cotyledons infected by $S$. sclerotiorum revealed that the interaction induced changes in the composition of the pool of soluble metabolites (Fig. 1, Fig. 2 and Table 1). A decrease in sugars and amino acids was observed. The total carbohydrate level was only 59 and $57 \mu \mathrm{mol} \mathrm{g}{ }^{-1} \mathrm{FW}$ of infected tissues, 24 and $48 \mathrm{hpi}$, whereas it was 125 and $179 \mu \mathrm{mol} \mathrm{g}^{-1} \mathrm{FW}$ in plant and fungal tissues, respectively. More specifically, fructose and sucrose, initially present almost exclusively in plant, were reduced by $85 \%$. These results suggest that plant carbohydrate stores were utilized for fungal growth.

Analyses of ${ }^{13} \mathrm{C}$-NMR spectra also revealed changes in the composition of the pool of storage carbohydrates: inositol, the plant polyol marker, decreased from 10 to $2.1 \mu \mathrm{mol} \mathrm{g} \mathrm{g}^{-1}$ FW of infected tissues 48 hpi (Fig. 1, Table 1). Trehalose, a specific fungal carbohydrate remained constant during infection, whereas the level of mannitol, the main fungal polyol, revealed a 4-fold increase from 24 to 48 hpi. This may suggest that trehalose did not constitute the main carbohydrate endogenous store in fungus, whereas mannitol was actively 
1 polyol was detected neither in plant nor in fungus cultivated separately. During infection, free 2 glycerol increased steadily, reaching 23-25 $\mu \mathrm{mol} \mathrm{g}^{-1} \mathrm{FW} 48$ hpi. Additional experiments 3 indicated that S. sclerotiorum accumulated glycerol but not mannitol as compatible osmolyte, when cultivated for $24 \mathrm{~h}$ in a hyper-osmotic medium containing $0.4 \mathrm{M} \mathrm{NaCl}$ (data not shown). Therefore, glycerol synthesis could occur in reaction to osmolarity changes possibly associated to the release of metabolites by dying plant cells or contribute to the osmotic stabilization of the hyphae required for invasive growth through tissues of living plants.

Glutamate and alanine, the two main free amino acids of plant or fungal origin, were detected in infected cotyledons at 24 and 48 hpi. Glutamate, initially abundant both in plant and mycelium, decreased strongly during the first hours of infection (data not shown), reaching less than $10 \%$ of the initial values $24 \mathrm{hpi}$, then increasing to $22 \% 48 \mathrm{hpi}$. Alanine, initially much more abundant in mycelium, accumulated moderately throughout the development of infection (Fig. 1, Table 1).

Carbohydrate and amino acid storage in cotyledons was also affected at distance during fungal infection. For example, 40 to $50 \%$ decrease in glucose, fructose, sucrose and glutamate was observed 24 hpi in the non-invaded region of leaves, beyond the infected area (data not shown). This suggests that the fungus behaves as a sink towards the metabolites required for its own growth, at the expense of plant stores.

${ }^{31} \mathrm{P}-\mathrm{NMR}$ spectra first showed the appearance of tre-6-P and a dramatic increase of UDP-GlcNAc, reflecting the rapid proliferation of fungal hyphae in infected cotyledons tissues. The concentration of GPC in infected tissues increased simultaneously, reaching the one of GPI (Fig. 2). Accumulation of GPC in plant cells often reveals a stress, leading to partial hydrolysis of phospholipids (Aubert et al. 1996). Thus, its increase in infected tissues could indicate that fungal invasion gave rise to plant membrane systems hydrolysis and to subsequent release of metabolites in the apoplast. As GPC is the most abundant phosphodiester in S. sclerotiorum mycelium (Table 1), its presence in infected cotyledons may also reflect fungal growth in plant tissues.

Detection of invertase in infected cotyledons

Analysis of ${ }^{13} \mathrm{C}-\mathrm{NMR}$ spectra revealed that sucrose, present exclusively in plant, decreased from 11 to $2.1 \mu \mathrm{mol} \mathrm{g}^{-1}$ during the first $24 \mathrm{hpi}$ and was not detectable $48 \mathrm{hpi}$. The disappearance of sucrose from infected sunflower cotyledons could likely be correlated with 
1 activity or plant enzymes activated in response to the fungal attack, we used a biochemical 2 approach to investigate the presence of invertase during infection. Plants contain different isoforms of invertases, which can be distinguished by their subcellular location and biochemical properties (Godt and Roitsch 1997). To assess an invertase enzymatic activity in planta, proteins were extracted from healthy and infected sunflower cotyledons. Except for 0 and $48 \mathrm{hpi}$, infected tissues were separated in two regions: healthy tissues not colonized (region a) and invaded tissues (region b). Proteins were separated by IEF over a $\mathrm{pH}$ range of 3-10. Invertase activity was revealed at $\mathrm{pH} 5.6$ and visualized by staining reducing sugars in the gel. Two isoforms (pI 4 and 4.5) were detected (Fig. 3a). Invertase activity associated to the protein with $\mathrm{pI}$ of 4.5 was detected in healthy sunflower cotyledons and remained constant until 24 hpi. Thereafter, plant tissues were totally macerated. On the contrary, the presence of the invertase isoform with a $\mathrm{pI}$ of 4 was correlated with the presence of the fungus in the infected plant. Invertase activity was hardly detectable 8 hpi (region 8 b), then increased strongly at $24 \mathrm{hpi}$ (region 24b) and $48 \mathrm{hpi}$. Detection of invertase activity was also performed at $\mathrm{pH} 4$ and 7 and revealed, at a lower level, the same pattern of activity for the protein with a $\mathrm{pI}$ of 4 , while no activity was detected at $\mathrm{pH} 4$ and 7 for the isoform with a pI of 4.5 (data not shown). This indicates that the activities of both enzymes were detected using favourable $\mathrm{pH}$ conditions. In order to reveal the fungal or plant origin of the major invertase activity detected at a $\mathrm{pI}$ of 4, we used immuno specific detection. Western blot analyses (Fig. 3b, c) revealed two isoforms, differing in their molecular weight and separately detected by antibodies raised against a fungal invertase (Fig. 3b) and a plant cell wall invertase (Fig. 3c). A $81 \mathrm{kDa}$ isoform was abundantly detected by anti-fungal invertase antibodies and its presence was limited to regions severely colonized by $S$. sclerotiorum ( $24 \mathrm{~b}$ and $48 \mathrm{hpi}$ ). The $40 \mathrm{kDa}$ isoform, detected by anti-plant invertase antibodies exhibited a different pattern and was present in healthy tissues and during infection during the first $24 \mathrm{hpi}$. This isoform was not detected $48 \mathrm{hpi}$ when sunflower cotyledons were completely invaded and macerated. This protein was consequently not linked to the fungus but rather correlated with the presence of healthy plant tissues. The presence of the $81 \mathrm{kDa}$ isoform paralleled the invertase activity detected at at $\mathrm{pI} 4$ and could likely be attributed to the fungus. Analyses of biochemical properties of the fungal invertase expressed during in vitro growth in the presence of $10 \mathrm{mM}$ sucrose, confirmed our suggestions. Figure $3 \mathrm{~d}$ revealed an unique active isoform at $\mathrm{pI} 4$, released in the culture medium by $S$. sclerotiorum during $36 \mathrm{~h}$ growth in the presence of sucrose, that corresponds to the isoform detected in plant tissues (Fig. 3a). Moreover, western blot analyses conducted with proteins of the same origin and anti-fungal invertase antibodies (data not shown), 
1 revealed a band of $81 \mathrm{kDa}$, corresponding to the isoform detected in planta (Fig. 3b). These

results strongly suggested that the major acid invertase activity detected during infection was mainly of fungal origin.

\section{Expression of fungal hexose transporters during infection}

Pathogenic fungi must feed on their hosts. During pathogenesis of sunflower cotyledons, plant stores and particularly carbohydrates are likely transferred in the fungal mycelium, which suggests that the fungal plasma membrane is equipped with corresponding transporters. Thus, two genes Sshxt1 and Sshxt2, encoding hexose transporters from S. sclerotiorum, have been isolated. For this purpose, EST sequences from the related necrotrophic fungus B. cinerea, identified in public databases (Soanes et al. 2002) and showing several convincing matches to fungal hexose transporters were used as probes to screen at low stringency the genomic EMBL3 library of $S$. sclerotiorum. Two recombinant phages giving the strongest hybridization signals were chosen for further studies. Restriction and Southern analyses allowed to clone and to characterize two sequences of 2133 and 2099 bp containing the coding sequences of $S s h x t 1$ and $S s h x t 2$, respectively. Each sequence had two introns. SsHXT1 and SsHXT2 possess 12 membrane-spanning domains (Fig. 4) characteristic for members of the major facilitator super family (Marger and Saier 1993). The GRR or GRK conserved regions are implicated in the membrane topology of this group of transporter proteins (Sato and Mueckler, 1999). Sequences analyses and databases searches revealed that SsHXT1 and SsHXT2 contain a five-element fingerprint that provides a signature for the sugar transporter family of membrane proteins (InterProScan, Zdobnov and Apweiler 2001). The presence of a conserved Phe residue, situated in the transmembrane domain X, implicated in the specificity of the transport, was also detected in all sequences (Özcan and Johnston 1999). Highly conserved regions identified within the fructose transporters as fungal fructose-proton symporter signatures and found in BcFRT1, a fructose transporter present in B. cinerea (Doehlemann et al. 2005), were not detected in SsHXT1 and SsHXT2 sequences. Thus, SsHXT1 and SsHXT2 contain the main sugar transport signatures but are probably not sole fructose transporters.

Recently, the release of the genome sequence of $S$. sclerotiorum (http://www.broad.mit.edu) offered new opportunities to identify sugar transporters sequences. A Blast search for possible homologies with SsHXT1 revealed, for the first hits, at least six additional sequences. These proteins belong to the family of membrane proteins 
1 responsible for the transport of sugars, as revealed by the InterProScan database (Zdobnov and Apweiler 2001). To illustrate the relatedness of these and other sequences, a dendrogram was generated (Fig. 5). Sugar transport sequences do not form a uniform group. It clearly showed that SsHXT1 and SsHXT2 clustered together (46\% identity to each other) and were related to ApHXT1, an A. parasiticus monosaccharide transporter (Yu et al. 2000) with respectively 30.3 and $34.3 \%$ identity. Five other sequences were more related to the $N$. crassa glucose sensors NcRCO3 (Madi et al. 1997) and the monosaccharide transporter AmMSTA (Nehls et al. 1998), a candidate gene encoding an homologue to the glucose sensors Rgt2 and Snf3 in Saccharomyces cerevisiae (Wei et al. 2004). Among these five sequences, three (SsIG 028441, SsIG 066201 and SsIG 084251) were predicted to be high affinity transporters by the databases (InterProscan, Zdobnov and Apweiler 2001), whereas a separated branch contained a $B$. cinerea fructose transporter and one S. sclerotiorum putative hexose transport sequence (Ss1G 030921).

In planta expression of Sshxt1 and Sshxt2 genes was analyzed. Relative levels of Sshxt1 and Sshxt2 mRNAs were determined using real-time Q-PCR (Fig. 6). In these experiments, mRNA level for the stably expressed fungal gene encoding actin Ssact1, was evaluated as control gene for Q-PCR analyses. Total mRNAs were extracted from infected tissues collected 8, 12, 24, 36 and $48 \mathrm{~h}$ after inoculation. Analysis of the expression profiles of $S s h x t 1$ and $S s h x t 2$ revealed wave expression patterns with a maximum of transcripts reached 36 hpi. Expression levels of $S s h x t 1$ and $S s h x t 2$ were not similar. Sshxt1, contrary to $S s h x t 2$, was highly expressed during infection. The high level of expression of Sshxt1 suggested that this gene is predominantly implicated in hexose transport during pathogenesis of sunflower cotyledons.

\section{Discussion}

This study reports on metabolic profiles of a necrotrophic interaction between the widespread pathogen S. sclerotiorum and sunflower cotyledons as host plant. For this purpose, the NMR spectroscopy offered an elegant way to build up a foundation of metabolic informations about nutrition of a necrotroph fungal pathogen during infection.

Analyses of the natural abundance spectra revealed the progressive exhaustion of plant carbohydrates stores like sucrose and fructose. Simultaneously, fungal activities implicated in sucrose degradation and hexose transport were expressed. Upon compatible interactions of plants with pathogenic fungi, plant carbohydrate metabolism is affected. An increase in 
1 extracellular invertase activity, the inverse regulation of photosynthesis and carbohydrates 2 withdraw from the plant by the pathogen, creates a sink which reflects the switch from normal metabolism to defence metabolism (Roitsch et al. 2003). The precise origin of the increase in invertase activity remains controversial, as both host and pathogen possess soluble and insoluble invertases. Therefore, it is difficult to establish whether the invertase activity stimulation is due to activation or to an increase in the amount of host proteins, or to a fungal invertase. The major plant invertases activated during a compatible interaction with biotrophic fungi are described as acid insoluble (cell wall-bound) enzymes (Benhamou et al. 1991; Scholes et al. 1994; Fotopoulos et al. 2003; Voegele et al. 2006). Acid soluble (vacuolar) and cytoplasmic invertase isoforms do not exhibit a major increase of their expression during biotrophic interactions, but are thought to be implicated in the metabolism of stored plant sucrose (Roitsch et al. 2003; Voegele et al. 2006). Our study elucidated the origin of the invertase activity detected in tissues infected by $S$. sclerotiorum. The use of specific antibodies directed against plant or fungal invertases revealed that much of the increase in activity could be attributed to a fungal isoform. In contrast to biotrophs, S. sclerotiorum triggers cell death (Dickman et al. 2001) and subsequently feeds as a saprophyte, which suggests that hexoses transported to the fungus are more likely the product of a fungal than a plant invertase. During infection, the acid invertase activity from plant origin did not support any increase and disappeared at the final stage of colonization, but a rise in fungal invertase expression was observed. During in vitro growth in the presence of sucrose, the fungal invertase was also produced and secreted in the culture medium. Voegele et al. (2006) reported on the appearance of a secreted fungal invertase during the biotrophic interaction of U. fabae with $V$. faba. While sink soluble plant invertases seem to be cell wall bound, this might not be the case for the respective enzymes provided by the pathogen. Involvement of fungal invertase in pathogenesis has only been demonstrated in the compatible biotrophic $V$. $f a b a / U$. fabae interaction (Voegele et al. 2006) and for the necrotrophic parasite $B$. cinerea (Ruiz and Ruffner 2002). Thus, our results contribute to establish that fungal invertase expression takes part to fungal plant pathogenesis and to the necrotrophic strategy of $S$. sclerotiorum.

Sucrose degradation and hexose sugar consumption were coordinated, as the expression of the hexose transporters genes Sshxt1 and Sshxt2 reached maximal values 36 hpi, before decreasing at the latter stage of infection. Interestingly, levels of expression of Sshxt1 and $S s h x t 2$ differed. Sshxt 2 was weakly expressed and was quantified as twenty times lower than 
1 be related to specific ambient parameters created during infection. By lowering the ambient 2 environmental $\mathrm{pH}$, oxalic acid may affect the transcriptional regulation of $\mathrm{pH}$-regulated genes necessary for pathogenesis and developmental life cycle of S. sclerotiorum (Cotton et al. 2004; Bolton et al. 2006). Extracellular hexose concentration is also a non-negligible control element. Glucose level reached $63 \mathrm{mM}$ in healthy cotyledons, then $50 \mathrm{mM} 48 \mathrm{hpi}$, which may favour the expression of low affinity hexose transporters. However, soluble intracellular sugars and hexoses released from cell wall and storage polymers degradation could be present, but inaccessible during the first hours of infection. As revealed by detection of a fungal invertase activity, sucrose degradation is actively performed until the end of infection and, consequently, should be correlated with a transport activity. The decreasing level of expression observed for both transporters $36 \mathrm{hpi}$, strongly suggests that additional transporters are necessary to support growth and development during the late stage of infection. Thus, a multiple transport system is likely to be expressed in S. sclerotiorum during pathogenesis. A screening for putative transporters-encoding genes revealed at least six additional sequences in the $S$. sclerotiorum genome. Candidate genes encoding, among others, homologues to sugar sensors (predicted to be high affinity transporters) or fructose transporters were revealed by the dendrogram. Therefore, $S$. sclerotiorum possesses a multigenic sugar transport system that could provide an efficient and flexible tool to this broad host range pathogen. Transcriptional analyses conducted during in vitro growth and functional characterizations of transporters should provide new insights on regulation, specificity and affinity of those transport proteins. The disappearance of sucrose in infected sunflower cotyledons, the expression of an invertase activity together with the expression of fungal hexose transporters are consistent with glucose and fructose being the sugars transferred from the host tissues to the pathogen. Even healthy parts of leaves also exhibited a loss of sugars, indicating that S. sclerotiorum was able to uptake nutrients from a distance.

During infection, strong modifications of NMR profiles reflecting the hydrolytic activity of the necrotroph were detected. The invasion of plant tissues was marked by an important rise of GPC and GPE levels, probably triggered by the attack of membrane polar lipids (Aubert et al. 1996). These data suggest that autolysis of the host membrane occurred. Fungal enzymes, such as phospholipases, are expressed during pathogenesis and could contribute to the degradation of these molecules (Lumdsen 1970). Moreover, these data are consistent with the behaviour of S. sclerotiorum which is able to elicit host cell death and the fact that necrotrophic pathogens may need to trigger plant apoptotic pathway for successful colonization and subsequent disease development (Dickman et al. 2001). 
The evolution in fungal trehalose and polyol contents was also followed during the course of infection. Trehalose, the second most abundant sugar accumulated in $S$. sclerotiorum mycelium, is a common storage product within microbial cell and especially in spores. Increased trehalose levels in fungi also have been correlated with cell survival under adverse conditions (Arguelles 1997). Trehalose was not accumulated during sunflower cotyledon infection and remained at a very low level. Infection-related development and colonization of host tissues could require the pathogen to mobilize storage carbohydrates. Trehalose mobilization has been involved in virulence-associated functions that follow host colonization in the pathogenic fungus Magnaporthe grisea (Foster et al. 2003). The absence of stored trehalose may also reflect a deviation of the fungal metabolites oriented toward an increased production of protective polyols such as glycerol. In filamentous fungi, polyols such as mannitol, glycerol, arabinitol and erythritol are widely distributed and can be accumulated to a high concentration (Jennings 1984). Their intracellular concentrations depend on growth conditions and developmental stages, suggesting that polyols have important functions in fungal physiology. Mannitol was the only polyol detected in the mycelium of S. sclerotiorum cultivated in vitro. It was produced by the fungus in planta. A 4-fold increase was noticed in infected tissues from 24 to $48 \mathrm{hpi}$, whereas the amount of UDP-GlcNAc, that could reflect the evolution of the fungal biomass only doubled. Mannitol production, through the mannitol cycle (Jennings 1984) could be supplied by the degradation of sucrose from plant origin, particularly by an active conversion of fructose. Mannitol is considered as an important intermediate in the physiology of fungi (Jennings 1984). This hexilitol can be stored in fungal hyphae, or further metabolized in order to store reducing power or constitute a reserve carbon source (Ruijter et al. 2003). Secretion of mannitol is thought to directly protect invading pathogens by quenching host-produced reactive oxygen species (Jennings et al. 2002). In ectomycorrhizas, NMR spectroscopy investigations, to characterize carbohydrate metabolism during symbiotic state, revealed greater allocation of glucose to the synthesis of short chain polyols, whereas sucrose decreased in colonized roots (Martin et al. 1998). In the necrotrophic fungal pathogen Stagonospora nodorum, mannitol has been implicated in fungal plant interaction by revealing the incapacity of the mutant to sporulate in planta (Solomon et al. 2006). Levels of mannitol found in apoplastic fluids of infected leaves and in extracts of spores were observed to rise dramatically in the biotrophic interaction of the rust $U$. fabae with its host plant (Voegele et al. 2005). Thus, symbiotic or pathogenic interactions trigger similar metabolic responses, like an increase in mannitol production that could be a key regulatory component of carbon flow. 
Contrary to mannitol, glycerol was not detected in S. sclerotiorum mycelium

2 diring in vitro growth, but it appeared in tissues from the first hours of infection. During the invasion process, glycerol increased by a factor of 5.4 from 24 to 48 hpi. By contrast, glycerol-3-P initially present in fungus and fairly abundant in the host plant, decreased during mycelium proliferation. Previous studies showed that, in plants, glycerol permeates all cell compartments and is phosphorylated very efficiently in the cytoplasm (Aubert et al. 1994). We have verified that sunflower cotyledons (healthy as well as infected) also phosphorylated an exogenous source of glycerol in a very efficient manner (data not shown). We could therefore suggest that the glycerol observed in infected tissues was not localized in plant but was in the fungal hyphae during host plant invasion, where it was very likely synthetized and where it accumulated without permeating outside fungal hyphae. Subsequent modification of the fungal wall, like melanization, should render the hyphae non permeable to glycerol. For M. grisea, mechanical pressure derived from elevated osmotic pressure within melanized appressoria, through the accumulation of glycerol (Howard and Ferrari, 1989). Melanization, which has been described in the sclerotial stroma of S. sclerotiorum (Bolton et al., 2006), could also be implicated in the modification of the infection hyphae. The amount of glycerol accumulated during infection was 4 times higher than that of mannitol, which characterized the mycelium during in vitro growth. During infection a metabolic switch could occur. Mannitol could be replaced by glycerol. However, the origin of this metabolic response remains to be elucidated. During $M$. grisea appressorium turgor generation, glycerol accumulation is a consequence of lipolysis (Wang et al. 2005). During the infection of sunflower cotyledons, glycerol could be a by-product of the degradation of lipids stored in germinations and subsequently accumulated by the fungus as a carbon storage compound. Alternatively, glycerol has also been reported as a compatible solute assuming osmotic stress protection necessary to maintain fungal cell expansion (Han and Prade 2002). We have observed that glycerol can abundantly accumulate in S. sclerotiorum under an osmotic stress provoked by addition of sodium chloride to the culture medium, while the mannitol content remained constant. Thus, glycerol could play a prominent role in osmostress adaptation. Osmoregulation during the course of pathogenesis has been demonstrated in the phytopathogenic fungus $C$. fulvum. In that case, arabinitol was the main polyol to respond to reduced water availability in planta and in vitro (Clark et al. 2003). Glycerol could play the same role in S. sclerotiorum where its accumulation could generate a turgor pressure essential for penetration of the fungus. As suggested by Voegele et al. (2005), conversion of carbohydrates taken up by the fungus into polyols would also maintain a gradient of 
1 metabolites toward the pathogen to support fungal development. Our results argue that 2 metabolism and transport of soluble carbohydrates are of significance during plant pathogen 3 interactions. During infection, the necrotrophic pathogen, S. sclerotiorum produces a drastic depletion of nutrients in plant tissues. The strong carbohydrate sink capacity of the fungus is linked to the presence of a multigenic hexose transport system and the expression of a fungal invertase during infection. Once transferred to the parasite, plant carbohydrates are likely to be converted in polyols. By enhancing penetration and draining capacities, accumulation of mannitol and glycerol in planta are likely to sustain the degradative strategy of $S$. sclerotiorum. The present study revealed the involvement of a fungal invertase during the necrotrophic pathogenesis of S. sclerotiorum, and the exclusive production of glycerol in planta. Molecular and biochemical analyses in these directions may help for developing new knowledge about the pathogenesis of necrotrophic fungi.

Acknowledgements This work was supported by grants from the Ministère de la recherche, CNRS, the Université de Lyon, and the Région Rhône-Alpes. CJ was supported by a doctoral scholarship from the Région Rhône-Alpes. We thank AJ Dorne and MH Lebrun (Plant and Fungal Physiology, UMR 2847 CNRSBayerCropScience, Lyon, France) for helpful comments. We are also indebt to JL Lebail for his dedicated technical assistance with the NMR spectrometer.

\section{References}

Abood JK, Lösel DM (2003) Changes in carbohydrate composition of cucumber leaves during the development of powdery mildew infection. Plant Pathol 52:256-265

Arguelles JC (1997) Thermotolerance and trehalose accumulation induced by the heat shock in yeast cells of Candida albicans. FEMS Microbiol Lett 146:65-71

Aubert S, Gout E, Bligny R, Douce R (1994) Multiple effects of glycerol on plant cell metabolism, phosphorus-31 nuclear magnetic resonance studies. J Biol Chem 269:21420-21427

Aubert S, Gout E, Bligny R, Marty-Mazars D, Barrieu F, Alabouvette J, Marty F, Douce R

Bago B, Pfeffer PE, Douds DD, Brouillette J, Bécard G, Shachar-Hill Y (1999) Carbon metabolism in spores of the arbuscular mycorrhizal fungus Glomus intraradices as revealed by nuclear magnetic resonance spectroscopy. Plant Physiol 121:263-271 
1 Benhamou N, Grenier J, Chrispeels MJ (1991) Accumulation of B-fructosidase in the cell walls of tomato roots following infection by a fungal wilt pathogen. Plant physiol 97:739-750

Berger S, Papadopoulos M, Scheriber U, Kaiser W, Roitsch T (2004) Complex regulation of gene expression, photosynthesis and sugar levels by pathogen infection in tomato. Physiol Plant 122:419-428

Boland GJ, Hall R (1994) Index of plant hosts of Sclerotinia sclerotiorum. Can J Plant Pathol 16:93-108

Bolton MD, Thomma BPHJ, Nelson BD (2006) Sclerotinia sclerotiorum (Lib.) de bary: biology and molecular traits of a cosmopolitan pathogen. Mol Plant Pathol 7:1-6

Cabib E, Silverman SJ, Shaw JA, Das Gupta S, Park H-M, Mullins JT, Mol PC, Bowers B (1991) Carbohydrates as structural constituents of yeast cell wall and septum. Pure \& Appl Chem 63:483-489

Chen J, Saxton J, Hemming FW, Peberdy JF (1996) Purification and partial characterization of the high and low molecular weight forms (S-and F-form) of invertase secreted by Aspergillus. Biochim Biophys Acta 1296:207-218

Chou H-M, Bundock N, Rolfe SA, Scholes JD (2000) Infection of Arabidopsis thaliana with Albugo candida (white blister rust) causes a reprogramming of host metabolism. Mol Plant Pathol 1:99-113

Clark AJ, Blisset KJ, Oliver RP (2003) Investigating the role of polyols in Cladosporium fulvum during growth under hyperosmotic stress and in planta. Planta 216:614-619

Cotton P, Kasza Z, Bruel C, Rascle C, Fèvre M (2003) Ambient pH controls the expression of endopolygalacturonase genes in the necrotrophic fungus Sclerotinia sclerotiorum. FEMS Microbiol 227:163-169

Dickman M, Park Y, Oltersdorf T, Li W, Clemente T, French R (2001) Abrogation of disease development in plants expressing animal antiapoptotic genes. Proc Natl Acad Sci USA 98:6957-6962

Doehlemann G, Molitor F, Hahn M (2005) Molecular and functional characterization of a fructose specific transporter from the gray mold fungus Botrytis cinerea. Fungal Genet Biol 42:601-610

Foster AJ, Jenkinson JM, Talbot NJ (2003) Trehalose synthesis and metabolism are required at different stages of plant infection by Magnaporthe grisea. EMBO J 22:225-235

Fotopoulos V, Gilbert MJ, Pittman JK, Marvier AC, Buchanan AJ, Sauer N, Hall JL, Williams LE (2003) The monosaccharide transporter gene, AtSTP4, and the cell-wall 
invertase, At $\beta$ fruct1, are induced in Arabidopsis during infection with the fungal biotroph Erysiphe cichoracearum. Plant Physiol 132:821-829

Godt DE, Roitsch T (1997) Regulation and tissue-specific distribution of mRNAs for the extracellular invertase isoenzymes of tomato suggests an important function in establishing and maintaining sink metabolism. Plant Physiol 115:273-282

Hall JL, Williams LE (2000) Assimilate transport and partitioning in fungal biotrophic interactions. Aust J Plant Pathol 27:549-559

Han K-H, Prade RA (2002) Osmotic stress-coupled maintenance of polar growth in Aspergillus nidulans. Mol Microbiol 43:1065-1078

Hegedus DD, Rimmer SR (2005) Sclerotinia sclerotiorum: When "to be or not to be" a pathogen? FEMS Microbiol Lett 251:177-184

Henning-Vainstein M, Peberdy JF (1991) Location of invertase in Aspergillus nidulans: release during hyphal wall digestion and secretion by protoplasts. Mycol Res 95:12701274

Howard FJ, Ferrari MA (1989) Role of melanin in appressorium function. Exp Mycol 13:403418

Jennings D (1984) Polyol metabolism in fungi. Adv Microbial Physiol 25:149-193

Jennings DB, Daub ME, Pharr DM, Williamson JD (2002) Constitutive expression of a celery mannitol dehydrogenase in tobacco enhances resistance to the mannitol-secreting fungal pathogen Alternaria alternata. Plant J 32:41-19

Joosten MHAJ, Hendrickx LJM, De Witt PJGM (1990) Carbohydrate composition of apoplastic fluids isolated from tomato leaves inoculated with virulent and avirulent races of Cladosporium fulvum (syn. Fulvia fulva). Neth L Plant Pathol 96:103-112

Laemmli UK (1970) Cleavage of structural proteins during the assembly of the head of the bacteriophage T4. Nature Lond 277:680-685

Lumdsen RD (1970) Phosphatidase of Sclerotinia sclerotiorum produced in culture and in infected bean. Phytopathology 60:1106-1110

Lumdsen RD, Dow RL (1973) Histopathology of Sclerotinia sclerotiorum infection of bean. Phytopathology 36:708-715

Madi L, McBride SA, Bailey LA, Ebbole DJ (1997) rco-3, a gene involved in glucose transport and conidiation in Neurospora crassa. Genetics 146:499-508

Marger MD, Saier MH (1993) A major superfamily of transmembrane facilitators that catalyse uniport, symport and antiport. Trends Biochem Sci 18:13-20 
Martin F, Boiffin V, Pfeffer PE (1998) Carbohydrate and amino acid metabolism in the Eucalyptus globulus Pisolithus tinctorius ectomycorrhiza during glucose utilization. Plant Physiol 118:627-635

Maxwell DP, Lumdsen RD (1970) Oxalic acid production by Sclerotinia sclerotiorum in infected beans and in culture. Phytopathology 60:1395-1398

Mendgen K, Struck C, Voegele RT, Hahn M (2000) Biotrophy and rust haustoria. Physiol Mol Plant Pathol 56:141-145.

Nehls U, Wiese J, Guttenberger M, Hampp R (1998) Carbon allocation in ectomycorrhiza: identification and expression analysis of an Amanita muscaria monosaccharide transporter. Mol Plant-Microbe Interact 11:167-176

Noeldner PKM, Coleman MJ, Faulks R, Oliver RP (1994) Purification and characterization of mannitol dehydrogenase from the tomato pathogen Cladosporium fulvum (syn. Fulvia fulva). Physiol Mol Plant Pathol 45:281-289

Özcan S, Johnston M (1999) Function and regulation of yeast hexose transporters. Microbiol Mol Biol Rev 63:554-569

Ratcliffe RG, Shachar-Hill Y (2001) Probing plant metabolism with NMR. Annu Rev Plant Physiol Plant Mol Biol 52:499-526

Riou C, Freyssinet G, Fèvre M (1991) Production of cell wall-degrading enzyme by the phytopathogenic fungus Sclerotinia sclerotiorum. Appl Environ Microb 57:1478-1484

Roberts JKM, Jardetsky O (1981) Monitoring of cellular metabolism by NMR. Biochim Biophys Acta 639:53-76

Roitsch T, Balibrea ME, Hofmann M, Proels R, Sinha AK (2003) Extracellular invertase: key metabolic enzyme and PR protein. J Exp Bot 382:513-24

Ruijter GJG, Bax M, Patel H, Flitter SJ, van de Vondervoort PJI, de Vries RP, vanKuyk PA, Visser J (2003) Mannitol is required for stress tolerance in Aspergillus niger conidiospores. Eukaryotic Cell 2:690-698

Ruiz E, Ruffner HP (2002) Immunodetection of Botrytis-specific invertase in infected grapes. J Phytopathol 150:76-85

Sambrook J, Fritsch EF, Maniatis T (1989) Molecular cloning: a laboratory manual, $2^{\text {nd }}$ edn. Cold Spring Harbor, NY:Cold Spring Harbor Laboratory Press

Sato M, Muckler M (1999) A conserved amino acid motif (R-X-G-R-R) in the Glut1 glucose transporter is an important determinant of membrane topology. J Biol Chem 274:24721-24725 
Scholes JD, Lee PJ, Horton P, Lewis DH (1994) Invertase: understanding changes in the photosynthetic and carbohydrate metabolism of barley leaves infected with powdery mildew. New Phytol 126: 213-222

Shachar-Hill Y, Pfeffer PE (1996) Nuclear magnetic resonance in plant physiology. American Society of Plant Physiologists, Rockville, MD, pp 260-274

Sinha AK, Hofmann G, Köckenberger, Elling L, Roitsch T (2002) Metabolizable and nonmetabolizable sugars activate different signal transduction pathways in tomato. Plant Physiol 128:1480-1489.

Soanes DM, Skinner W, Keon J, Hargreaves J, Talbot NJ (2002) Genomics of phytopathogenic fungi and the development of bioinformatic resources. Mol PlantMicrobe Interact 15:421-427

Solomon PS, Waters ODC, Jörgens CI, Lowe RGT, Rechberger J, Trengove RD, Oliver RP (2006) Mannitol is required for sexual sporulation in the wheat pathogen Stagonomosra nodorum. Biochem J 399:231-239

Struck C, Mueller E, Martin H, Lohaus G (2004) The Uromyces fabae UFAAT3 gene encodes a general amino acid permease that prefers uptake of in planta scarce amino acids. Mol Plant Pathol 5:183-189

Tang X, Rolfe SA, Scholes JD (1996) the effect of Albugo candida (white blister rust) on the photosynthetic and carbohydrate metabilosm of leaves of Arabidopsis thaliana. Plant Cell Environ 19:967-975

Towbin H, Staehelin T, Gordon J (1979) Electrophoretic transfer of proteins from polyacrylamide gels to nitrocellulose sheets: procedure and some applications. Proc Natl Acad Sci USA 76:4350-4354

Voegele RT, Struck C, Hahn M, Mendgen K (2001) The role of haustoria in sugar supply during infection of the broad bean by the rust fungus Uromyces fabae. Proc Natl Acad Sci USA 98:8133-8138

Voegele RT, Hahn M, Lohaus G, Link T, Heiser I, Mendgen K (2005) Possible roles for mannitol and mannitol dehydrogenase in the biotrophic plant pathogen Uromyces fabae. Plant Physiol 137:190-198

Voegele RT, Wirsel S, Möll U, Lechner M, Mendgen K (2006) Cloning and characterization of a novel invertase from the obligate biotroph Uromyces fabae and analysis of expression patterns of host and pathogen invertases in the course of infection. Mol Plant-Microbe Interact 19:625-634 
1 Wang Z-Y, jenkinson JM, Holcombe LJ, Soanes DM, Veneault-Fourrey C, Bhambra GK,

2

3

4 5

6

7

8 Talbot NJ (2005) The molecular biology of appressorium turgor generation by the rice blast fungus Magnaporthe grisea. Biochem Soc Trans 32:384-388

Wei H, Vienken K, Weber R, Bunting S, Requena N, Fischer R (2004) A putative high affinity hexose transporter hxtA, of Aspergillus nidulans is induced in vegetative hyphae upon starvation and in ascogenous hyphae during cleistothecium formation. Fung Genet Biol 41:148-156

Yu J, Chang P-K, Bhatnagar D, Cleveland TE (2000) Cloning of a sugar utilization gene cluster in Aspergillus parasiticus. Biochim Biophys Acta 1493:211-214

Zdobnov EM, Apweiler R (2001) "InterProScan-an integration platform for the signaturerecognition method in InterPro". Bioinformatics 17:847-848 
1 Table 1 Metabolic profiling of $S$. sclerotiorum mycelium, $H$. annuus healthy cotyledons and 2 infected cotyledons collected 24 and $48 \mathrm{hpi}$. Metabolites are identified and quantified from a 3 series of experiments, using maleate and methylphosphonate as internal standards for ${ }^{13} \mathrm{C}$ - and $4{ }^{31} \mathrm{P}-\mathrm{NMR}$, respectively, as indicated in Materials and methods. Values are given as $\mu \mathrm{mol} \mathrm{g} \mathrm{g}^{-1}$ 5 FW. nd: not detected. Results are given as mean \pm SD $(n=3)$

\begin{tabular}{|c|c|c|c|c|}
\hline Metabolite & $\begin{array}{l}\text { Healthy } \\
\text { cotyledons }\end{array}$ & $\begin{array}{l}\text { Infected } \\
\text { cotyledons } \\
(24 \mathrm{hpi})\end{array}$ & $\begin{array}{l}\text { Infected } \\
\text { cotyledons } \\
(48 \mathrm{hpi})\end{array}$ & $\begin{array}{l}\text { S. sclerotiorum } \\
\text { mycelium }\end{array}$ \\
\hline $\begin{array}{l}\text { Total } \\
\text { carbohydrate }\end{array}$ & $125 \pm 10$ & $59 \pm 5$ & $57 \pm 5$ & $179 \pm 12$ \\
\hline $\begin{array}{l}\text { Glucose } \\
\text { Fructose }\end{array}$ & $\begin{array}{l}63 \pm 5 \\
40 \pm 4\end{array}$ & $\begin{array}{l}35 \pm 3 \\
20 \pm 2\end{array}$ & $\begin{array}{l}50 \pm 4 \\
7.0 \pm 0.6\end{array}$ & $\begin{array}{l}115 \pm 12 \\
2.3 \pm 0.2\end{array}$ \\
\hline Sucrose & $11 \pm 1$ & $2.1 \pm 2$ & nd & $<1.0$ \\
\hline Trehalose & nd & $1.3 \pm 0.2$ & $1.0 \pm 0.02$ & $26 \pm 3$ \\
\hline Glycerol & nd & $4.4 \pm 0.3$ & $24 \pm 2$ & nd \\
\hline Inositol & $10 \pm 1$ & $3.3 \pm 0.3$ & $2.1 \pm 0.2$ & nd \\
\hline Mannitol & nd & $1.3 \pm 0.2$ & $5.6 \pm 0.6$ & $27 \pm 3$ \\
\hline Malate & $6.8 \pm 0.5$ & $7.2 \pm 0.4$ & $2.4 \pm 0.2$ & $12 \pm 1$ \\
\hline Succinate & $3.5 \pm 0.3$ & $3.7 \pm 0.3$ & $1.2 \pm 0.2$ & $1.0 \pm 1$ \\
\hline Citrate & $2.5 \pm 0.2$ & $3.5 \pm 0.3$ & $1.2 \pm 0.2$ & nd \\
\hline Fumarate & $23 \pm 2$ & $27 \pm 2$ & $23 \pm 2$ & $6.0 \pm 1$ \\
\hline Glutamate & $18 \pm 2$ & $1.9 \pm 0.2$ & $4.0 \pm 3$ & $17 \pm 2$ \\
\hline Alanine & $1.0 \pm 0.2$ & $<1.0$ & $2.4 \pm 0.2$ & $8.0 \pm 1$ \\
\hline $\mathrm{Pi}$ & $2.5 \pm 0.2$ & $2.1 \pm 0.2$ & $2.90 \pm 0.3$ & $2.7 \pm 0.3$ \\
\hline Glucose-6-P & $0.86 \pm 0.06$ & $0.78 \pm 0.6$ & $0.63 \pm 0.5$ & $1.2 \pm 0.1$ \\
\hline Trehalose-6-P & nd & $0.07 \pm 0.02$ & $0.14 \pm 0.015$ & $0.55 \pm 0.05$ \\
\hline Glycerol-3-P & $0.67 \pm 0.05$ & $0.12 \pm 0.01$ & $0.16 \pm 0.015$ & $0.19 \pm 0.02$ \\
\hline PGA & $0.13 \pm 0.02$ & $0.2 \pm 0.02$ & $0.2 \pm 0.02$ & $0.23 \pm 0.02$ \\
\hline P-choline & $0.50 \pm 0.04$ & $0.39 \pm 0.04$ & $0.23 \pm 0.03$ & nd \\
\hline GPG & $0.54 \pm 0.04$ & $0.45 \pm 0.04$ & $0.38 \pm 0.04$ & $<0.04$ \\
\hline GPE & $<0.04$ & $0.06 \pm 0.01$ & $0.21 \pm 0.02$ & $0.37 \pm 0.04$ \\
\hline GPI & $0.98 \pm 0.07$ & $0.72 \pm 0.06$ & $0.68 \pm 0.06$ & $0.18 \pm 0.015$ \\
\hline GPC & $0.07 \pm 0.01$ & $0.31 \pm 0.03$ & $0.68 \pm 0.06$ & $0.90 \pm 0.07$ \\
\hline ATP & $0.16 \pm 0.015$ & $0.18 \pm 0.02$ & $0.18 \pm 0.02$ & $0.35 \pm 0.03$ \\
\hline NAD & $0.08 \pm 0.01$ & nd & nd & $0.04 \pm 0.01$ \\
\hline NADP & $0.055 \pm 0.006$ & nd & nd & $0.12 \pm 0.01$ \\
\hline
\end{tabular}




$\begin{array}{lllll}\text { UDP-Glc } & 0.25 \pm 0.03 & 0.22 \pm 0.03 & 0.35 \pm 0.04 & 0.89 \pm 0.07 \\ \text { UDP-GlcNAc } & <0.04 & 0.29 \pm 0.03 & 0.57 \pm 0.05 & 1.4 \pm 0.12\end{array}$

Figure legends

Fig. 1a-c. ${ }^{13} \mathrm{C}-\mathrm{NMR}$ spectra of S. sclerotiorum mycelium (a), H. annuus cotyledon (b) and sunflower cotyledons infected by S. sclerotiorum 48 hpi (c). Perchloric extracts were prepared from $10 \mathrm{~g}$ fresh material as described in "Materials and methods". ${ }^{13} \mathrm{C}-\mathrm{NMR}$ spectra (100.6 $\mathrm{MHz}$ ), recorded at $20^{\circ} \mathrm{C}$, were the result of 900 transients (90 min). Peak assignments are as follows: Ala, alanine; cit, citrate; fru, fructose; fum, fumarate; glc, glucose ;Glu, glutamate; gly, glycerol; ins, inositol; mal, malate; mnt, mannitol; n.i., not identified; scn, succinate; suc, sucrose; tre, trehalose. Prominent fungal compounds are indicated in bold in panel c. Panels on the right show a focused region of each spectra

Fig. 2a-c Proton-Decoupled in vitro ${ }^{31} \mathrm{P}-\mathrm{NMR}$ spectra of $S$. sclerotiorum mycelium (a), $H$. annuus cotyledon (b) and sunflower cotyledons infected by S. sclerotiorum 48 hpi (c). Perchloric extracts were prepared from $10 \mathrm{~g}$ fresh material as described in "Materials and Methods". Spectra (161.9 MHz) recorded at $20^{\circ} \mathrm{C}$ were the result of 1024 transients $(60 \mathrm{~min})$. Peak assignments are as follows: fru-6-P, fructose-6-phosphate; glcn-6-P, gluconate-6-P; glc6-P, glucose-6-P; gly-3-P, glycerol-3-P; man-6-P, mannose-6-phosphate; P-cho, phosphorylcholine; PEP, phosphoenolpyruvate; P-eth, phosphorylethanolamine; phy, phytate; $\mathrm{Pi}$, inorganic phosphate; poly-P, polyphosphates; tre-6-P, trehalose-6-P; UDP-glc, UDPglucose; UDP-gal, UDP-galactose. The internal reference is not shown. Spectra are representative of three independent experiments. Prominent fungal compounds are indicated in bold in panel c

Fig. 3a-d Detection of soluble invertase in planta and in vitro. All lanes were loaded with 10 $\mu \mathrm{g}$. For lanes $8 \mathrm{a}, 8 \mathrm{~b}, 24 \mathrm{a}$, and 24b infected cotyledons were cut in half. Lanes $8 \mathrm{a}$ and 24a correspond respectively to healthy regions of infected cotyledons 8 and 24 hpi, lanes $8 \mathrm{~b}$ and $24 \mathrm{~b}$ correspond to regions colonized by S. sclerotiorum 8 and 24 hpi. Samples were prepared on an equal leaf area. a Isoelectrofocusing pattern of invertase produced during the time course of infection of sunflower cotyledons by $S$. sclerotiorum. Invertase activity was visualized by staining reducing sugars with TTC after incubation at $\mathrm{pH} 5.6$. b and c Immunospecific detection of plant and fungal invertases in infected sunflower cotyledons 
1 extracts revealed respectively with anti-C. albicans invertase and anti-tobacco invertase. d

2 Isoelectrofocusing pattern of $S$. sclerotiorum invertase produced after $36 \mathrm{~h}$ of growth on 10 $3 \mathrm{mM}$ sucrose medium. Lane 1, protein standards stained with Coomassie blue ; lane 2, 4 invertase activity revealed as in section a. Western blots and IEFs were repeated at least twice 5 . 4

Fig. 4 Conserved amino acid stretches for fungal monosaccharide transporters. Locations of the conserved sequences, in SsHXT1 and SsHXT2, are indicated by numbering above the SsHXT1 sequence. Residues conserved in all seven transporters homologues are shaded in grey. Black bars indicate transmembrane domains of SsHXT1. Conserved domains were deduced from the alignment of the following protein sequences obtained by using the CLUSTALW algorithm and are positioned by arrows on the SsHXT1 sequence. Abbreviations and accession no. are as follows: S. sclerotiorum SsHXT1 (AY647267), S. sclerotiorum SsHXT2 (AY647268), U. fabae UfHXT1 (AJ310209), T. harzianum ThGTT1 (AJ269534), A. muscaria AmMST1 (ZZ83828), A. parasiticus ApHXT1 (AF010145), B. cinerea BcFRT1 (AY738713)

Fig. 5 Phylogram of hexose transporters-related proteins from S. sclerotiorum and other fungi. Consensus tree prediction was performed by using multiple sequence alignment, by cluster algorithms with the TreeTop-Phylogenetic Tree prediction program (GenBee). Numbers represent the percentage of occurrence obtained after bootstrap analysis (1000 random samples) of the phylogenetic tree. Abbreviated species names are as indicated in Fig. 4 and as follows: N. Crassa RCO3 (accession no. U54768), A. nidulans AnMSTA (accession no. AJ535663). Other putative S. sclerotiorum sequences (Ss1G_084251, Ss1G_066201, Ss1G_054561, Ss1G_060321, Ss1G_028441, Ss1G_030921) are predicted proteins obtained from the Sclerotinia sclerotiorum Sequencing Project, Broad Institute of Harvard and MIT (http://www.broad.mit.edu) according to InterProScan databases (Zdobonov and Apweiler, 2001). Sequences from S. sclerotiorum are underlined

Fig. 6 Relative Sshxt1 and Sshxt2 expression analyzed by Q-PCR during time course of sunflower cotyledon infection. Relative expression levels were normalized with respect to Ssact1 expression levels 